\title{
TAKING PRUDENCE SERIOUSLY
}

\author{
Guy Fletcher
}

\section{INTRODUCTION}

Philosophers have long theorised about which things make people's lives go well, and why, and the extent to which morality and self-interest can be reconciled. ${ }^{1}$ By contrast, we have spent little time on meta-prudential questions, questions about prudential discourse. ${ }^{2}$ This is surprising given that prudence is, prima facie, a normative form of discourse and, as such, cries out for further investigation of how exactly it functions and whether it has problematic commitments. ${ }^{3}$ It also marks a stark contrast from moral discourse, which has been extensively theorised about.

By 'prudential discourse' I mean two things. Firstly, thought and talk about what's good/better/best for or bad/worse/worst for, harms, benefits (etc) someone. Secondly, thought and talk about what someone prudentially ought to do, has reason to do, must do, or needs to do, along with analogous claims about attitudes. ${ }^{4}$ Prudential discourse thus encompasses evaluative prudential discourse ('good for' etc) and deontic prudential discourse ('ought prudential etc). ${ }^{5}$ Here are some paradigmatic instances:

'You'll be better off if you have the surgery.'

'Her spouse's death was terribly bad for her.'

'Sarah should take the job.'

'You need friends in order to live well.'

The big picture meta-prudential questions that prudential discourse gives rise to include (at least):

\section{Are prudential judgements normative judgements?}

\footnotetext{
${ }^{1}$ Acknowledgements: I am indebted to (at least) the following for various forms of help with this chapter: Debbie Roberts, Daniel Groll, Bart Streumer, Steve Campbell, Connie Rosati, Daniel Haybron, Kathryn Lindeman, Eric Wiland, Uriah Kriegel, Eden Lin, Alex Gregory, Sarah Stroud, Joey Van Weelden, Richard Chappell, Elinor Mason, James Brown, Mike Ridge, Teemu Toppinen, Daniel Wodak, Justin Snedegar, Jason Raibley, Krister Bykvist, Chris Cowie, Louise Hanson, Marcy Lascano, Richard Rowland, Jack Woods, Pekka Väyrynen, Anandi Hattiangadi, Jonas Olson, audiences in Edinburgh (*2), Montreal, Dublin, Geneva, Paris, St Louis, Rome, California Long Beach, and The Madison Metaethics Workshop. Sincere thanks also to two anonymous referees, whose comments were invaluable.

${ }^{2}$ Some exceptions to this are Railton (1989), Hooker (1991), Rosati (1995a, 1995b, 1996), Darwall (2004).

${ }^{3}$ Much of the history of moral philosophy presumes that prudential normativity is genuine and more easily justifiable than moral normativity. c.f. Darwall (2016).

${ }^{4}$ A complication: 'good for' (etc) talk extends beyond welfare subjects (beings with levels of well-being). For example: 'oil is good for engines', 'sand is bad for watches'. How to draw the boundary between these uses of 'good for' and those connected to well-being is an issue that I bracket here. See Kraut (2007), Fletcher (2012, $\mathrm{ms})$, Finlay (2014), Rosati (ms).

5 'Deontic' is an imperfect label, I grant.
} 
2. Does prudential discourse involve the ascription of normative properties (in either a deflationary sense or a robust sense) and, if robust, what is the nature of prudential properties?

3. Do evaluative prudential properties generate prudential reasons?

4. Is prudential talk partly (or wholly) expressive?

Herein, I explicitly take up questions 1 and 3. Some of my discussion bears on question 2 but I leave question 4 (and others) for another day.

Here is the plan. I first $(\$ 2)$ examine whether there is a distinct set of prudential reasons, generated by evaluative prudential properties. I do so because this is an important issue in its own right but also because points that arise there bear on the later discussion. I argue that there are prudential reasons (and that prudential reasons of one sort are compatible with Humeanism about reasons for action). More precisely, my thesis there is:

Prudential Value Matters (PVM): Evaluative well-being facts generate agent-relative reasons (for action or for attitudes) for the relevant agent.

In the second half of the chapter (\$\$3-5) I take up question 1, asking whether prudential discourse is normative. ${ }^{6}$ To motivate doing so, note that many think it obvious whether prudential discourse (etc) is normative. ${ }^{7}$ Unfortunately, they disagree. Moreover, their discussion of the question tends to be in passing. On the positive side we have Steve Finlay, who writes:

There is close isomorphism between morality and self-interest. For one thing, each is a normative domain: there is a moral "ought" and an "ought" of self-interest. ${ }^{8}$

And David Enoch who writes:

Paradigmatic examples may however help clarify the kind of things I refer to as normative[:] that I should go on a diet, that you have a reason to read Kant $[\ldots]$ that pain is pro-tanto bad for the person whose pain it is[.․]

${ }^{6}$ For analogous inquiries into other prima facie normative properties and domains, see Schroeder (2015) and Sylvan (2018).

${ }^{7}$ I think it is fair to attribute to them the implicit view that the answer is obvious by the limited amount of space they spend arguing for their respective views. The 'etc' here is because some of these claims are specifically about concepts, some about properties, some about domains. Nonetheless, I think that they are all fairly interpreted as about prudential discourse.

${ }^{8}$ Finlay (2007: 138). 
By contrast, others contend that prudential discourse is non-normative. Bart Streumer comments:

$[T]$ hat a painting is beautiful can be a reason to look at it and can make it wrong to destroy it, and being a reason and being wrong are normative properties. But that does not mean that beauty is itself a normative property. [S]imilar claims apply to disgust, funniness, harm, benefit $[.]^{10}$

And Jonas Olson writes:

The second consideration that makes me hesitant to accept the idea that welfare should be seen as a normative concept is purely economical. We have a plethora of normative concepts already[.] Why introduce yet another one if it seems that we can do without it? ${ }^{11}$

To simplify things, I will assume that some region of discourse is normative if the judgements essential to it are normative judgements. Thus, I will argue that prudential discourse is normative by arguing for the following thesis:

Prudential Judgements are Normative (PJN): Prudential judgements are normative judgements.

A natural retort at this point: What makes a judgement a normative judgement? Before outlining my strategy for establishing PJN, let me introduce and set aside three alternate proposals whose weaknesses are instructive.

First, I do not answer the question of what makes a judgement a normative judgement via some meta-normative theory. For instance, if one characterises normative judgements as essentially involving ascription of non-natural, irreducibly normative, properties then one's characterisation has immediately assumed a form of non-naturalism or robust realism (or error theory). ${ }^{12}$ By contrast, if one characterises normative judgements as essentially desire-like states then one has immediately assumed a form of noncognitivism (and the same goes for other parochial proposals). It is not my ambition here to argue for a specific meta-prudential theory, only the more minimal thesis that prudential discourse is a normative form of discourse. I thus need a less parochial way of characterising normative judgements.

\footnotetext{
${ }^{9}$ Enoch (2011: 1). The reading example could be read differently — as a moral reason to read — but the other examples are plausibly prudential.

${ }^{10}$ Streumer (2017: 105) (my italics).

11 Olson (2006: 176). Granted, Olson's claim is specifically about the concept WELFARE.

${ }^{12}$ For discussion of various options for characterising what makes a property normative, see Streumer (2017: §45).
} 
Second, I do not want to treat the normativity of prudential judgements as settled by the fact that such judgements are made using evaluative and deontic terms. The trouble with this test alone is that there are many kinds of judgements that deploy evaluative and deontic vocabulary that seem not to belong in the same theoretical category as e.g. moral judgements, the paradigmatic instance of normative judgement. ${ }^{13}$ Familiar examples here are judgements about attributive goodness — good kettles and good toasters etc — the rules of clubs and games, legal judgements, and etiquette judgements. Though these judgments are normative in some sense of 'normative' they are not normative in the way moral judgements are.

Third, one might suggest that prudential judgements are normative if they ascribe properties that entail normative reasons. Unfortunately this proposal collapses the distinction between normative properties and normatively-relevant properties (and between normative judgements and normativelyrelevant judgements). ${ }^{14}$ Many judgements ascribe properties that entail normative reasons but not all of these are plausibly normative judgements themselves. For example: 'a phone is ringing in the cinema', 'the fridge is empty', 'that's a snake' are judgements that ascribe properties that entail normative reasons without themselves being normative judgements. I thus don't want to characterise normative judgements in terms of reasons-entailment. ${ }^{15}$

The alternate strategy that I will pursue I call the 'parity strategy'. This is to argue for PJN by analogy with moral discourse. It is widely held that morality is a normative domain. Thus if we can find relevant similarities between moral judgements and prudential judgements, and no significant disanalogy, that gives us grounds for holding that prudential judgements are normative. I will pursue such a strategy, arguing, first (\$3), that the features of moral judgements that metaethicists appeal to when articulating, explaining, and justifying the claim that moral judgements are normative are also possessed by prudential judgements. I then $(\$ 4)$ consider various objections to the analogy.

\section{PRUDENTIAL REASONS}

We are accustomed to thinking that well-being at least sometimes generates normative reasons because at least some moral duties (etc) are explained by facts about making lives go better or worse. Without denying that, the question here is not whether well-being generates normative reasons at all. Rather, it is whether there are specifically prudential reasons (which are distinct from moral reasons and the like).

What must be true for there to be normative prudential reasons (I henceforth sometimes suppress 'normative' for brevity)? There are prudential reasons if and only if the following is true:

\footnotetext{
13 I use 'normative' in the broad(er) sense that encompasses the evaluative rather than contrasting with it.

14 This distinction (in terms of facts) comes from Parfit (1997).

15 What about necessary reason-entailment? I think not. Pleasure and pain facts are plausible candidates for being necessarily reason-entailing without, themselves, being normative facts.
} 
Prudential Value Matters (PVM): Evaluative well-being facts generate agent-relative reasons (for action or for attitudes) for the relevant agent. ${ }^{16}$

To better understand PVM it is useful to look at two general ways of denying it (I consider instances of each strategy shortly). ${ }^{17}$

One way to deny PVM is to allow that things are (e.g.) good for people but deny that such facts generate distinctly prudential reasons. ${ }^{18}$ Thus one might reject the existence of prudential reasons by holding that all reasons for action, even if generated by well-being, are agent-neutral.

A second way to deny PVM is to hold that there are agent-relative reasons for an agent (to e.g. promote their own well-being) but deny that these reasons are fundamentally generated by evaluative well-being facts. This would be true if one thought that all reasons were generated by some other property $\mathrm{P}$ and that sometimes an agent's promoting their own well-being had property $\mathrm{P}$. Thus, on this view, an agent sometimes has reasons to act in ways that will, in fact, promote their own well-being but this reason does not stem from the fact that by so acting they will promote their own well-being but instead from the P property of the outcome.

We now know what must be true for there to be prudential reasons. Are there any? It seems like there are. Across many decision-making contexts, one assesses options at least partly with an eye to which is in one's best interests. When deciding which career to take up, one considers among other things how the options will impact one's well-being. One might choose to be a lecturer rather than an aid worker because, although better impartially, the latter option will be worse for oneself. How to weigh these competing considerations is, of course, difficult. But it seems plausible that, in such decisions, one factor we weigh against the moral reasons we have is a set of reasons to promote and secure our own good.

The same seems true for smaller decisions (joining a gym, going on holiday). Suppose you are asked why you did something. Just as 'it was the right thing to do' serves as a justification for performing some action in most, perhaps all, contexts, so to 'it was best for me' serves as a justification across many circumstances. ${ }^{19}$ So evaluative prudential properties seem to generate prudential reasons for action. Why, then, would someone deny such prudential reasons?

\subsection{Objection 1: All Reasons are Agent Neutral}

\footnotetext{
${ }^{16}$ I leave aside the buck-passing proposal that there are prudential reasons but generated (only) by the grounds of evaluative well-being properties. Though I think this incorrect, I lack the space to address it in full. I don't deny that the grounds of evaluative well-being properties can generate reasons.

17 Another way to deny PVM is via the view that nothing is (e.g.) good for anyone. This is not a view that I expect many to hold. For this reason, and constraints of space, I pass over discussing it.

${ }_{18}^{18}$ For example, Nagel (1970), Worsnip (2018), Hayward (forthcoming).

${ }^{19}$ I take the plausibility of this - that something's being your best option gives you prudential reason to choose it - to undermine Scanlon's (1998) scepticism about the normative importance of well-being. For discussion see Fletcher (ms).
} 
One ground for denying PVM is the view all reasons are agent-neutral. This would be the view, for example, of someone who accepted a very broad form of utilitarianism (that well-being is the sole fundamental generator of all reasons for action) who denied that a person's well-being generates distinctive reasons for themselves, over and above the moral reasons that everyone's well-being generates for everyone. ${ }^{20}$

What is the difference between agent-relative and agent-neutral reasons ${ }^{21}$ Whilst there is no consensus on how precisely to draw the distinction, ${ }^{22}$ we get the general idea via cases such as:

Case 1

$\begin{array}{ccc} & \text { Vikram's Well-Being } & \text { Julia's Well-Being } \\ \text { Option 1 } & 500 & 1000 \\ \text { Option 2 } & 600 & 901\end{array}$

Suppose you must decide which option to bring about. Vikram and Julia are strangers (to you and each other). One reason that you have for choosing option 2 over option 1 - the greater total well-being is plausibly fully general (or agent-neutral).

Now, suppose that Julia is making the decision (Vikram and Julia are still strangers to each other). If there are agent-relative reasons then the situation is now different in the following way. Whilst Julia has a reason to choose option 2 that is exactly like one you had, there is also a reason for Julia to choose option 1, namely that her own well-being is higher under that scenario. Those who claim that all reasons are agent-neutral must deny the existence of this reason for Julia. On their view, there is no difference in the reasons that you or Julia would have in making these decisions.

I think that such a view is implausible for reasons for action and we can see that by considering this type of case:

Case 2

\begin{tabular}{lcc}
\multicolumn{2}{r}{ Vikram's Well-Being } & Julia's Well-Being \\
Option 1 & 500 & 1 \\
Option 2 & 1 & 500
\end{tabular}

Suppose $I$ am making the decision between these options and that there are no further relevant differences between these two outcomes and these two people are perfect strangers. In such a situation,

\footnotetext{
20 This would be a very broad view because it would be utilitarianism about not only moral reasons but all practical reasons.

${ }_{21}$ The terminology of agent-neutral vs agent-relative was introduced by Parfit (1984). The modern debate about such reasons stems from Nagel (1970).

22 For detailed discussion of the extant proposals, see Ridge (2017).
} 
I need some way of resolving the tie between these outcomes (flipping a coin etc) because there is no reason to choose one option over another in terms of total well-being or any other fully general consideration. If all reasons are agent-neutral then it follows that, if Julia were in the position of choosing in this case, then she too would need to (e.g.) flip a coin in order to decide between these options. But that seems highly implausible. Presumably her own well-being can be a tie-breaker in this case, giving her some reason to choose option 2 . This suggests that there are agent-relative prudential reasons, even if they only serve to break ties.

However, note that PVM is compatible with the denial of agent-relative reasons for action as long as there can be agent-relative reasons for attitudes. And this seems especially plausible. Looking again at case 2, would it not be mistaken for Vikram and Julia to be completely indifferent to which option I choose, given the huge difference in their well-being on each option ${ }^{23}$ Don't they each have a reason to prefer the outcome in which they do much better? I take this to be evidence that there are prudential reasons for attitudes at the very least.

\subsection{Objection 2: Humeanism about Reasons}

Let me now return to the second general objection to PVM. This objection allows for agent-relative reasons for an agent to e.g. promote their own well-being but, crucially, denies that these reasons are generated by evaluative well-being facts themselves. The most likely species of this genus assumes the truth of a Humean or 'internalist' theory of reasons so I will examine that one in particular.

On a Humean theory of reasons all reasons for action stem from, and are explained by, an agent's desires. Whenever someone has a reason to do something this is because the action is conducive to the fulfilment of a desire of theirs. Put more precisely:

Humeanism about Reasons for Action: $\mathrm{X}$ has a reason to iff and because -ing promotes the fulfilment of a desire of X's. ${ }^{24}$

One might wonder precisely why Humeanism would lead one to deny PVM. Remember, PVM is:

Prudential Value Matters (PVM): Evaluative well-being facts generate agent-relative reasons (for action or for attitudes) for the relevant agent.

\footnotetext{
23 Reminder: they are strangers to each other.

${ }^{24}$ For canonical recent defences of the view see Schroeder (2007) and Markovits (2014). For the sake of space I focus on this, standard, Humean view but many Humeans, and commentators, sophisticate the theory in different ways. Such ways include: allowing the reasons that an agent has to be explained by desires that they do not have but would have under some counterfactual condition (e.g. Williams 1981); allowing desires that the agent does not yet have but will have to be relevant (e.g. Lin 2015); allowing the desires of other agents to be relevant (e.g. Manne 2016). For dissent see, for example, Enoch (2005).
} 
In many cases Humeanism and PVM deliver identical verdicts about the existence of reasons; both say that the relevant agent has a reason to perform some action. That will be true in any case where an agent has a desire that is fulfilled by getting what is good for them.

However, Humeanism and PVM offer competing fundamental explanations of why the agent has the reason. On the Humean view, the fundamental explainer of the reason - that in virtue of which the agent has the reason — is the fact that the relevant action promotes the fulfilment of the agent's desire. For PVM, by contrast, the explainer of the reason is the fact that the option is good for the agent (and this reason remains in place even if the desire disappears). Thus the challenge to PVM posed by the Humean theory of reasons is not the view that there are no reasons to promote well-being. Rather, it is that there are no distinctively prudential reasons, reasons that are fundamentally explained by well-being. ${ }^{25} 26$

Having explained this challenge to PVM from the Humean view of practical reasons let us assess the prospects for prudential reasons. Of course, the viability of Humeanism about practical reasons is a major issue, one that would take rather more than one chapter to settle. I do not pretend to offer a decisive case against it. I aim only to point out, firstly, precisely bow counterintuitive it is when we consider prudence. I do this because it is easy to think that, unlike morality, Humeanism is not all that counterintuitive with respect to prudence. I also aim to show that Humeanism about reasons for action is compatible with the plausible claim that there are prudential reasons for attitudes, such that one can combine Humeanism and PVM.

Here are some cases to bring out how counterintuitive Humeanism is with respect to well-being:

Cult Colin: Colin is raised in a cult and believes his torment and suffering to be necessary for the sake of humanity. He has many desires including the desire to suffer for the sake of humanity. None of his desires would be fulfilled by escaping the cult. However, were he to escape, he would lead a life with a much higher level of well-being.

Depressed Dave: Dave is severely depressed. His condition leaves him with no desire that would be fulfilled by his continued existence. However, if he were to get medical help, he would go on to lead a life with a much higher level of well-being.

\footnotetext{
${ }^{25}$ For detailed discussion of these points see Worsnip (2018).

${ }^{26}$ The issues here are structurally similar to those concerning Humeanism and moral reasons. Humeans hold that morality and its demands cannot fundamentally generate reasons, only desires can. They then typically argue that on their view we still have reasons to do what morality requires by giving explanations of how conforming to the demands of morality in fact promotes the fulfilment of our desires. See, for example, Schroeder (2007).
} 
Educating Emily: Emily is a child who desires only to watch cartoons and eat ice cream. None of her desires would be fulfilled by going to school. However, were she to do so, she would lead a life with a much higher level of well-being.

In each case it is plausible that the relevant agent has a reason to perform some action, generated by evaluative well-being facts. ${ }^{27}$

These scenarios do not assume any first-order theory of well-being and we can generate these kinds of cases even assuming a desire theory of well-being. Take the simplest desire theory of well-being:

Desire Theory of Well-Being: something is good for someone if and only if and because it fulfils one of their actual desires.

Even on the assumption of this theory, PVM and Humeanism give different verdicts in the cases above. In the case of Colin, PVM plus the desire theory entails that Colin has reason to leave the cult so long as he would thereby end up with a larger set of fulfilled desires. Similarly, we get the verdict that Dave has (prudential) reason to seek help, stemming from the prudential value of that option (where that value comes from the desire-fulfillments within it).

Cases like these reveal one way in which Humeanism is revisionary about reasons and well-being. For in these scenarios, Humeanism entails (i) that the well-being that would be gained by performing some action is not, itself, a reason to do it and (ii) that the absence of a desire that would be fulfilled by performing the beneficial action entails that there is in fact no reason to perform the action. But this is extremely counterintuitive, especially in the case of Dave. Our sense that Dave has reason to get help is not undercut, I assume, by discovering that his depression is so bad that he has no desires served by getting help. Rather, this is evidence of just how strong are his reasons to get help.

Cases like Colin, Dave, and Emily put pressure on Humeanism by bringing out how revisionary it is when it comes to well-being in a way that is, I suggest, even starker than Humeanism's verdicts with respect to morality. ${ }^{28}$ We can accentuate it by considering a different case: ${ }^{29}$

Balanced Belinda: Belinda has a choice between two different career paths. Her desires are such that each option will promote the fulfilment of the same number of them (which are all of equal

\footnotetext{
27 For discussion of these issues, see Lin (2015).

${ }^{28}$ Starker, I think, because it is easy to think of internal reasons as being closely connected to one's own wellbeing (especially if one holds a desire-based view of well-being) and to fail to appreciate how often Humeanism will fail to deliver the reasons that we think agents have to promote their own well-being.

${ }^{29}$ Unlike the earlier cases, this case does require assuming the falsity of at least some forms of the desire fulfilment theory of well-being.
} 
intensity) so her desires leave the options weighted exactly equally. However, one option will give her a significantly higher level of well-being than the other.

Humeanism regards the two options as identical, in terms of reasons for action, given that each option promotes the fulfilment of the same number of desires (of equal intensity). But that is to think that no amount of extra well-being for one option can provide any normative weight, even as a tie-breaker. And that seems extremely counterintuitive. ${ }^{30}$ Couldn't someone recommend that Belinda take one of the options on precisely this prudential ground? And couldn't Belinda choose an option on this ground? If so, then it looks like prudential properties at least generate prudential reasons to break ties.

I have pointed out that Humeanism gives counterintuitive results in a range of cases. But reasons for action are not the only candidate here. Even if the foregoing fails, and Humeanism holds for reasons for action, PVM would still be true if there are prudential reasons for attitudes. ${ }^{31}$ We saw one example earlier (case 2) which demonstrated the plausibility of prudential reasons for attitudes. Here is another:

Ursula's Upgrade: Ursula is checking in for her flight. The person at the desk tells Ursula that she might get a free upgrade and that this will be decided between now and when she reaches the gate. Ursula will be better off if her ticket is upgraded.

In this case, Ursula does not have reason to do anything to get an upgrade, given that she cannot affect her chances. Presumably, though, she has reason to bope that she is upgraded, stemming from the fact that she would be better off. Further, this does not seem dependent upon Ursula having some relevant desire which the bope would promote the fulfilment of. Thus even if Humeanism is true for reasons for action, PVM could still be true because of prudential reasons for attitudes.

Let me recapitulate. In this section I argued that there are prudential normative reasons and tried to undermine two main challenges to them. In each case I pointed out the counterintuitive results that come from these denials of prudential reasons. I then showed, more concessively, how each is

\footnotetext{
${ }^{30}$ See Hayward (forthcoming) for a recent defence of the most stark dissenting view — that there are no normative requirements of prudence, even the sort of structural requirements people often think of as constitutive of rationality. See also Worsnip (2018).

${ }^{31}$ Is it peculiar to examine the possibility of Humeanism about reasons for action but not for attitudes? I do not deny that some will be Humeans about both. But it is hard to know what the orthodox Humean position is on this issue. Hume (1738: 2.3.3.6) famously declared there to be no reasons for preference: "Tis as little contrary to reason to prefer even my own acknowledg'd lesser good to my greater, and have a more ardent affection for the former than for the latter." (my italics) By contrast, contemporary Humeans typically leave unclear the extent to which their views extend beyond reasons for action. Two exceptions: Markovits (2014) — who is explicit in rejecting Humeanism for reasons for belief - and Cowie $(2014,2016)$ who explicitly extends his Humeanism to reasons for belief.
} 
compatible with the existence of prudential reasons for attitudes. I now move on to the second part of the chapter: whether prudential judgements are normative. ${ }^{32}$

\section{THE PARITY STRATEGY (I): THE POSITIVE CASE}

As I outlined at the beginning of the chapter, I will argue for this claim:

Prudential Judgements are Normative (PJN): Prudential judgements are normative judgements.

by looking at some of the grounds that are offered for the claim that moral judgements are normative (which I will call 'markers' of normativity) and arguing that they carry over to prudential judgement.

My claim is not that any of these alone is a sufficient condition of some judgement type being normative. It is easy to find false positives — namely, forms of non-normative judgements that have at least one of these features. However, it seems plausible that there are no forms of non-normative discourse that share all of them.

Finally, let me emphasise that these markers serve as evidence that some type of judgement is normative. I do not take them to constitute the nature of normative judgment. Normative types of judgements have these features (or at least some subset of them) because they are normative, whatever precisely that comes to, rather than being normative because they have these features. ${ }^{33}$

\subsection{MARKERS OF NORMATIVITY}

\subsubsection{Evaluative and Prescriptive}

One feature of moral judgements commonly cited in connection with their normativity is that they are evaluative, critical, or prescriptive.

Moral judgements do not merely represent how the world, agents, and their actions are. Rather they are about how the world or its constituents ought to be, how we have reason to make it, how it would be good, bad, better, best, or worst for it to be. This feature of moral judgements is reflected in the vocabulary in which they are made and expressed. We use deontic terms 'rights', 'wrong', 'permitted', evaluative terms 'good', 'bad', 'value', 'best' and modal terms 'ought', 'should', 'must'.

Here we find a perfect fit. Prudential judgements are equally evaluative, critical, or prescriptive. They do not merely represent how the world, agents, and their actions are but instead how the world or

\footnotetext{
32 It might be tempting to connect these two issues thus: if there are normative prudential reasons this means(at least some) prudential judgements are normative in virtue of their content. However, we do not need there actually to be any prudential reasons for these judgements to be normative in virtue of their content. Thus the truth of PVM, though sufficient, is not necessary to show that (some) prudential judgements are normative.

33 To expand: I take the points I am about to develop to be very general articulations of the data that we use when formulating and assessing metaethical views, data that must be explained, or explained away, by such views.
} 
its constituents ought to be, how we have reason to make it, how it would be good, bad, better, best, or worst for it to be. We also find the same evaluative ('good for', 'better for'), deontic ('reason'), and modal ( 'ought', 'should', 'must', 'needs') vocabulary used to make prudential judgements. ${ }^{34}$

\subsubsection{Authority}

Moral judgements are typically held up as having a kind of authority which in turn gives them a special place in deliberation.

It is often taken to be a feature of moral discourse that morality makes a difference to the reasons an agent has such that if an action is morally wrong this entails reasons for the agent not to perform that action and reasons for the agent to feel shame or guilt and to be blamed by others. ${ }^{35}$ This authoritative nature of morality is also reflected in the kind of centrality with which it is treated in deliberation where deciding what to do all-things-considered is closely connected with deciding what one morally ought to do. ${ }^{36}$ It is an everyday feature of conversation and deliberation that accepting that it would be morally wrong to perform some action is typically treated as settling whether one ought to do it all-things-considered. Furthermore, even where people allow that morality does not settle the question of what an agent ought to do all-things-considered, it is typically common ground that morality makes $a$ difference to what an agent ought to do, by entailing reasons.

Here we have a close fit between moral and prudential judgements. As argued above, prudential value plausibly makes a difference to the reasons an agent has; if an option is best for them then this gives them (at least) prudential reason to prefer that option.

One might be sceptical as to whether prudence has such a central role in deliberation as that which we find with morality. I agree that there is a less close connection between what one ought to do all-things-considered and what one prudentially ought to do. But this, I suggest, is specifically because moral demands plausibly trump prudential demands across many (though not all) contexts. If we focus on contexts where moral demands are screened off, the normative authority of prudence is clearer to see. In these contexts there is a close connection in between what one ought to do and what one prudentially ought to do; that some option would be (sufficiently) bad for you is treated as settling whether you ought to bring about that option (and vice versa for what would be best for you). Furthermore, in contexts where moral demands are in play, we treat prudential considerations as to-beweighed against moral requirements and one of the most plausible sets of cases where morality fails to settle what one ought to do all-things-considered is the set in which prudence (specifically, rather than

\footnotetext{
34 On the use of 'needs' in prudential discourse, see Fletcher (2018a).

35 That is not to deny the existence of scepticism on this point (e.g. the Why Be Moral? challenge).

36 I here assume the coherence of ought all-things-considered. c.f. Tiffany (2007), Baker (2017), Copp (ms).
} 
any other normative domain) trumps morality because morality's demands are too costly. This suggests that prudence enjoys the same kind of authority as morality. ${ }^{37}$

\subsubsection{Affective Connection}

For at least a central subset of moral judgements, there is a close connection between them and certain affective responses (including reactive attitudes).$^{38}$ For example, judging that morally I ought not to perform some action is closely connected to having some sorts of negative attitude towards it. We typically expect someone who makes the judgement that some action is morally wrong to blame and feel anger towards others who perform the action and guilt towards themselves if they perform such an action. And if an agent judges that, morally, they ought to perform some action we expect them (even if defeasibly) to be motivated to perform that action, in two senses of 'expect'. We make predictions about affective responses and motivation in light of moral judgements and we make these predictions on the basis that that an agent who falsified them would be criticisable in some way. ${ }^{39}$

Here, again, there is a perfect parallel with prudential judgment. ${ }^{40}$ In the case of prudential judgements, or at least the analogous central subset of them, we find a close connection between those judgements and affective responses (including reactive attitudes). Judging that an action is what one prudentially ought to do is closely connected to being motivated to perform that action and judging that some option would be best for oneself is closely connected to preferring that option. We similarly predict that agents have responses that line up with their prudential judgements and we make these predictions on the grounds that to lack such responses would be a failing.

\subsubsection{Disagreement}

Moral discourse is striking in the way that it permits of radical disagreement without manifestation of conceptual incompetence or loss of common subject-matter. ${ }^{41}$ People of radically divergent general world-views and across large differences in social and cultural milieu seem equally to make moral judgements and to be in the condition of agreeing and disagreeing morally, despite widespread differences in their wider set of beliefs. If there are limits to what one can think is morally wrong

\footnotetext{
37 Though, again, this depends on one's view about cases where prudence can override morality in determining what one ought to do all-things-considered.

38 'Close connection' is deliberately vague. The most hardcore of externalists about moral motivation can accept this thesis as long as they think it just notes a correlation.

${ }^{39}$ For representative discussion of these issues see (e.g.) Smith (1994), Svavarsdóttir (1999).

${ }^{40}$ Perhaps it is imperfect in this way: the connection is plausibly closer for prudential judgements than for moral judgements because every form of internalism about moral judgement and motivation is less plausible than the analogous claim about prudential judgement.

${ }^{41}$ See Hare (1952), Horgan \& Timmons (1992). For scepticism about the evidentiary value of such cases see Dowell (2016).
} 
without thereby showing oneself to be incompetent with moral concepts, these limits are lax, permitting a large range of fundamental moral disagreement. ${ }^{42}$

Here too we get a perfect fit. Prudential discourse also permits extremely radical disagreement, without manifestation of conceptual incompetence or loss of a common subject matter. In Welfare and Rational Care, Stephen Darwall provides an argument on precisely these lines:

$[1]$ t seems possible for two people who care about someone, $S$, to coherently disagree about whether something, $\mathrm{X}$, is good for $\mathrm{S}$, even though they agree completely about all the nonnormative facts concerning $\mathrm{X}$ and S. Suppose, for example, that $\mathrm{X}$ is a pleasant illusory belief of S's, say, that S's novel has sold 10,000 copies (when in fact it has sold only 12). It would seem that two people could be agreed about everything else, but simply disagree about whether this pleasant illusory belief is good for $\mathrm{S}$ or makes some contribution to his welfare, other things being equal... If this is right, then welfare...must be an explicitly normative concept. ${ }^{43}$

We can broaden out from illusory pleasant belief and note that people of radically divergent general world-views and across large differences in social and cultural milieu seem equally to make prudential judgements and to agree and disagree prudentially, despite widespread differences in their wider set of beliefs. Close to home, we have Nozick's experience machine example where some philosophers hold views of well-being where there is nothing prudentially deficient at all about life in the experience machine (assuming a large enough supply of hedons). ${ }^{44}$ By contrast, many philosophers think that such a life would hold little to no prudential value, because what matters prudentially is the exercise and development of our human capacities. Some philosophers think that getting what you want is what matters fundamentally, others think that some things have prudential value independently of whether we desire those things.

Moreover, it is easy to imagine radically different theories of prudential value across different communities (which thus constitute prudential 'twin earth' scenarios). ${ }^{45} \mathrm{We}$ can, for instance, imagine a pair of communities where one has a set of practices that suggests a bedonistic conception of prudential

\footnotetext{
${ }^{42}$ Foot (1958: 512) gives the example of thinking it morally wrong to look at hedgehogs in the light of the moon or run around trees right-handed. Perhaps this is a limit on what can count as a moral judgement. For the attempt to motivate a wide(r) range of conceptual restrictions on moral judgements see Cuneo \& Shafer-Landau (2014). I think that the same applies to prudence. Perhaps there are such fixed points when it comes to prudence. (e.g. one cannot coherently hold that the only thing with prudential value is looking at hedgehogs in the light of the moon.) Morality and prudence thus seem on a par here.

43 Darwall (2004: 10) gives this as a direct argument to argue for the view that prudential judgements are normative (along with his particular account of their content). This argument is criticised by Olson (2006) on the grounds that this disagreement phenomenon is found in non-normative, domains, such as genre judgements. Olson's objection succeeds, I think, against the argument that this feature suffices for a type of judgement to be normative.

${ }^{44}$ Nozick (1974: 42).

${ }^{45}$ On this see Fletcher (2018b).
} 
value whilst the practices in the other community suggests a perfectionist conception of prudential value.

In the first community, people advise their loved ones to only develop their capacities if by doing so they thereby maximise enjoyment, whereas in the second community they advise their loved ones to only seek pleasures where this is connected to the maximal exercise and development of their capacities. Similarly, in the first community those that are envied are the ones who experience most pleasure whilst in the second community it is those who develop and exercise their capacities most even if their lives are known to be less pleasurable. From cases like these it seems safe to say that prudential discourse, like moral discourse, permits a wide range of fundamental disagreement without talking past each other or manifesting conceptual incompetence.

To sum up this section, I have introduced four markers of the normativity of some set of judgements - four (sets of) ideas typically appealed to when articulating the normativity (and theoretical interest and importance) of moral judgements. I then argued that we find sufficiently close, often perfect, parallels in the case of prudential judgements. This gives us grounds for holding that prudential judgements are normative, on a par with moral judgements.

As I noted above, to show that prudential judgements are normative by analogy with moral judgements I need to establish relevant parallels between them and show that there is no significant disanalogy. In the next section I thus consider objections to the effect that there is a significant disanalogy between moral and prudential judgements and that PJN is false.

\section{OBJECTIONS TO PJN}

How might one argue that prudential and moral judgements are significantly disanalogous such that prudential judgements are not normative? In this section I consider three such objections. The first of these simply fails, as I shall explain. In response to the second and third I point out the considerable argumentative burdens which their proponent takes on.

\subsection{Objection 1: Prudential Value is Desire-Based}

The first such ground for rejecting PJN that one might offer is that prudential value is desire-based and that this means that prudential judgements are non-normative. Spelt out further, the argument is that a desire-based theory of well-being is true, that this entails that well-being properties are non-normative properties, which means that prudential judgements are non-normative. ${ }^{46}$ Because this objection to PJN assumes the truth of a particular first-order theory, I will talk in terms of prudential properties and facts (but this should be construed in a sufficiently minimal way so as to beg no questions between e.g. cognitivism vs non-cognitivism about prudential discourse).

\footnotetext{
46 As I read Mackie (1977: 29) he endorses this inference when considering the scope of his error theory: 'But if we think rather of a counsel of prudence as being related to the agent's future welfare, to the satisfaction of desires that he does not yet have — not even a present desire that his future desires should be satisfied — then a counsel of prudence is a categorical imperative, different indeed from a moral one, but analogous to it.'
} 
To fairly examine this objection, let us assume the following theory:

Desire Theory of Well-Being: Something is good for someone if and only if and because it fulfils one of their actual desires.

Would the truth of this theory entail that prudential properties and judgements are non-normative? No it would not. The argument assumes that the fact that something fulfils a person's desire is a nonnormative fact, which we can grant for the sake of argument. Would that suffice to show that the left hand side, the prudential fact, is a non-normative fact? No, that's too quick. Just because a prudential fact is explained by a non-normative fact it doesn't follow that it is a non-normative fact.

To see why, note the failure of the analogous argument for the non-normativity of morality, on the assumption of the dependence of the moral on the non-moral. Suppose this moral theory is true:

Moral Theory: It's morally wrong for X to PHI iff and because X's PHI-ing doesn't maximise pleasure.

On this kind of view, a fact about total pleasure that would be generated by an action — a paradigmatic non-normative fact - explains a moral fact. Does the truth of this explanatory claim, coupled with the right hand side being non-normative, mean that the moral fact is also a non-normative fact? Plainly not. We do not simply infer from the non-normative nature of the facts that make actions right and wrong that facts about rightness and wrongness are, themselves, non-normative. We find many cases where non-normative facts ground normative facts and even if one side of an explanatory claim is nonnormative it is a further question whether the fact on the left hand side is thereby non-normative.

Just to be clear about the dialectic here, my claim is that prudential value being desire-based would not entail that prudential properties and judgements are non-normative. For even if the facts that ground prudential facts are non-normative this does not, itself, settle the nature of prudential facts. ${ }^{47}$ And we can see that this inference is dubious by looking at other domains.

The way in which this argument fails extends to other theories of well-being. Just as the truth of a desire theory of well-being is insufficient to show that prudential properties and judgements are nonnormative, the truth of hedonism (or any other theory) would be similarly insufficient. Thus we cannot point to the non-normativity of the grounds of prudential facts to show that prudential properties and judgements are non-normative.

\subsection{Objection 2: Reductionism about Prudential Properties}

\footnotetext{
47 On this see Hampton (1998), Bedke (2009).
} 
Let us now consider a sophisticated successor to the objection that we just rejected. This objection holds that prudential properties are identical to desire-fulfilment properties and that is why prudential discourse is non-normative. To make maximally clear how this differs from the previous objection, on this new view it is not merely that desire-fulfilment has prudential value. Rather, what it is to be good for someone just is to fulfil their desire. This view thus suggests a reductive account of the evaluative prudential property of (e.g.) being good for someone. ${ }^{48}$ It combines this with the claim that such a reductive account entails that prudential judgements are non-normative.

This objection need not be run with the specific claim that it is desire-fulfilment that the property of being good for someone is identical to. Another natural candidate would be that evaluative prudential properties are identical to bedonic properties — such that to be good for someone just is to be pleasurable for them (and to be bad for someone just is to be painful for them).

What, then, to make of this objection? There are two weaknesses to it, in the form of heavy argumentative burdens which the objection incurs (burdens which make it difficult to provide a direct reply to the objection, without it being worked out in a lot more detail).

First, notice that for the objection to work, the objector must supply the reductive account of the property of being good for someone. This is, for reasons familiar from metaethics, no mean feat. As argued above, one of the normative markers of prudential discourse which it shares with moral discourse is the possibility of radical prudential disagreement. Such disagreement provides one obstacle to identifying the property of being good for someone with (e.g.) the property of fulfilling the person's desire (or, similarly, some hedonic property). ${ }^{49}$

The second argumentative burden that this strategy takes on is that of showing that the reductive account of the property of being good for someone entails that this property, and judgements ascribing it, are non-normative. Put another way, suppose that the property of being good for someone just is some hedonic property (and so on for the other evaluative prudential properties). The question now is: $w h y$ would that entail that prudential properties and judgements are non-normative? This strategy must therefore show why a form of reductive naturalism about prudential properties is incompatible with prudential judgements' being normative.

I do not claim to have shown that this kind of reductionist move against PJN cannot succeed. Space constraints preclude a comprehensive examination of this proposal. I have simply made that that is the task for anyone who pursues this strategy against PJN. Those inclined to reject PJN on the grounds of a reduction of prudential properties have much to do.

\subsection{Objection 3: Prudential Reasons are Different from Moral Reasons}

\footnotetext{
48 For discussion of the issues addressed here, see Schroeder (2005), (2007).

${ }^{49}$ See Heathwood (2009) for discussion of this issue.
} 
An analogous objection to the previous one, this time focused on deontic prudential properties, is the view that prudential reasons are not normative reasons (and so on for other deontic prudential properties). That is, someone might grant that there are prudential reasons, and oughts, etc but hold that these are somehow not normative or, at least, not normative in the way that moral reasons are. One model that might be appealed to is the idea that prudential reasons are like reasons (or 'reasons') of etiquette or that what it is for something to be prudentially required is similar to what it is for something to be required by law, or by a company code of conduct, or by etiquette. ${ }^{50}$ Another model would be that prudential reasons are hypothetical, rather than categorical, reasons.

We find instances of this position in the debate about what to do with moral discourse if error theory is true. In that debate, it is treated as utterly unproblematic to invoke prudential reasons within a dialectical context that supposes that there are no moral reasons (and perhaps no normative reasons whatsoever). For example, Richard Joyce writes:

But it is important to remind ourselves that even the eliminativist error theorist will still have plenty of good and strong reasons — many of them self- interested reasons_-for being nice to her fellows[. $]^{51}$

This passage, like many others in that debate, embodies a view of prudential reasons as non-normative (or, at least, as normative in some different, lesser, way than moral reasons).

It is important to distinguish between the claim that there are no prudential reasons (examined above) and this position, namely that there are prudential reasons but that they are not bona fide normative reasons of the sort that could make prudential judgements normative judgements on a par with moral judgements.

What could the difference between prudential and moral reasons consist in, such that prudential reasons are non-normative? As we saw above, it cannot be merely that prudential reasons are grounded in desires because a desire-fulfilment theory of well-being is true. That is compatible with their being normative. Rather, the property of being a prudential reason must be radically different from the property of being a moral reason, such that the prudential one is non-normative.

We also saw above that there is a genuine clash between Prudential Reasons and Humeanism about reasons. This means we cannot treat prudential reasons as distinct from moral reasons by treating them as hypothetical, rather than categorical, reasons. This is because, spelled out, this just is the view that there are no prudential reasons. If we have reasons to promote well-being only because that promotes the fulfilment of our desires, then that is to think that evaluative prudential facts themselves do not, fundamentally, generate reasons (which is, ipso facto, to deny that there are prudential reasons).

\footnotetext{
${ }^{50}$ For discussion see (e.g.) Dorsey (2016: ch.1), Olson (2011a, 2011b), Stroud (1998: 172).

${ }^{51}$ Joyce (2008: 75).
} 
There is thus no way of holding that there are prudential reasons and that they are non-normative by being internal / hypothetical.

As with the objection we considered in the previous section, the best version of the idea is that being a prudential reason just is some relation such as that of promoting fulfilment of the agent's desire, or generating pleasure for the agent. And, again, as with the previous objection, the person making this objection has two jobs to do. They must do the hard work of supplying a plausible reduction of the relation of being a prudential reason and show that this relation (and judgements ascribing it) are thereby non-normative. Furthermore, they must explain why prudential discourse (like moral discourse) possesses the markers of normativity, in stark contrast to the kinds of domains that might be appealed to as models for this reduction of prudential discourse (namely law, codes of conduct, and etiquette). ${ }^{52}$ Rhetorically: if prudential reasons are so different from moral reasons, why do they seem so similar?

Before moving on, let me note that whilst I considered the objections in sections 4.2 and 4.3 individually neither alone can be a fully general objection to PJN for the following reason - PJN encompasses evaluative and deontic judgements and each of these objections targets one of evaluative or deontic judgements. This means that these objections, individually, could only establish that one part of prudential discourse is non-normative. Someone who wanted to argue that prudential discourse is wholly non-normative must either (a) combine these objections (or similar ones) to show that neither evaluative nor deontic prudential judgements are normative or (b) collapse these tasks into one by treating all prudential normative properties as reducing to one and showing how that property (and judgements ascribing it) are reduced to something non-normative. ${ }^{53}$ These tasks are significant and it behoves those who wish to treat prudential normativity as second-class normativity to undertake them.

\section{CONCLUSION}

In this chapter I have argued for the following two claims:

Prudential Value Matters (PVM): Evaluative well-being facts generate agent-relative reasons (for action or for attitudes) for the relevant agent.

Prudential Judgements are Normative (PJN): Prudential judgements are normative judgements.

\footnotetext{
52 These domains have some of the markers but do not possess them all. In each case the connection to affect and motivation is implausible. It is also difficult (especially for codes of conduct and etiquette) to hold that there could be the same kind of radical disagreement.

${ }^{53}$ For example, a buck-passing view of all prudential properties would only need to provide one such reduction - of the property of being a prudential reason.
} 
I argued for PVM by showing how counterintuitive it is to deny that there are prudential reasons for action (or, at least, for attitudes). I argued for PJN by outlining the markers of normativity — features of moral discourse appealed to in defence of the claim that moral discourse is normative - and then showing that prudential discourse shares those features. I then considered objections to PJN, showing that these objections either fail or incur significant, hitherto undischarged, argumentative burdens.

If prudential judgement is normative, like moral judgement, this has a number of important implications throughout moral philosophy and metaethics. ${ }^{54}$ It means that we should examine prudential discourse directly, both for its own sake but also in order to assess various meta-normative theories. It's time to take prudence seriously.

54 On this see Fletcher (ms.) 


\section{References}

Baker, D. (2017) “Skepticism about 'Ought' Simpliciter.” In R. Shafer-Landau, ed., Oxford Studies in Meta-Ethics 12. (Oxford: OUP)

Bedke, M. (2009) 'Might all Normativity be Queer?', Australasian Journal of Philosophy, 88(1), 41-58.

Copp, D. (ms.) "Normative Pluralism and Skepticism about Ought Simpliciter."

Cowie, C. (2014) 'In defence of instrumentalism about epistemic normativity' Synthese, 191 (16): 4003-4017.

(2016) Revisionist Responses to the Amoralism Objection: A Reply to Julia Markovits. Ethical Theory and Moral Practice: 1-13.

Darwall, S. (2004) Welfare and Rational Care (Princeton: PUP).

. (2016) 'Making the "Hard" Problem of Moral Normativity Easier' in Lord, E. \& Maguire,

B.(eds.) Weighing Reasons (Oxford: OUP).

Dorsey, D. (2016) The Limits of Moral Authority (Oxford: OUP).

Dowell, J. (2016) 'The Metaethical Insignificance of Moral Twin Earth' in Russ Shafer-Landau (ed.), Oxford Studies in Metaethics, volume 11, (OUP).

Enoch, D. (2005) 'Why Idealize?’ Ethics, 115, 759-787.

(2011) Taking Morality Seriously (Oxford: OUP).

Fletcher, G. (2012) 'The Locative Analysis of Good For Formulated and Defended', Journal of Ethics \& Social Pbilosophy, 6, 1-26.

(2018a) 'Needing and Necessity' in Mark Timmons (ed.), Oxford Studies in Normative Ethics: volume 8 (Oxford: OUP).

(2018b) 'Pain for the Moral Error Theory: A New Prudential Companions-in-Guilt

Argument', Australasian Journal of Philosophy, 96(3), 474-482.

(ms) Dear Prudence.

Hampton, J. (1998) The Authority of Reason (Cambridge: CUP).

Hare, R. M. (1952) The Language of Morals (Oxford: OUP).

Hayward, M. K. (forthcoming) 'Practical Reason, Sympathy and Reactive Attitudes', Nô̂s.

Heathwood, C. (2009) Moral and Epistemic Open Question Arguments, Philosophical Books 50/2: 8398.

Hooker, B. (1991) 'Theories of Welfare, Theories of Good Reasons for Action, And Ontological Naturalism', Philosophical Papers, 20:1, 25-36.

Horgan, T. \& Timmons, M. (1991). 'Troubles for new wave moral semantics: The "open question argument" revived', Philosophical Papers, 21 (3), 153-75.

Joyce, R. (2008) 'Morality, schmorality' in Paul Bloomfield (ed.), Morality and Self-Interest (Oxford: OUP)

Kraut, R. (2007) What is Good and Why: The Ethics of Well-Being (Cambridge: HUP).

Lin, E. (2015) 'Prudence, Morality, and the Humean Theory of Reasons', Philosophical Quarterly, 65(259), 220-40.

Mackie, J. L. (1977) Ethics: Inventing Right and Wrong. (London: Penguin).

Manne, K. (2016) 'Democratizing Humeanism' in Lord, E. \& Maguire, B. (eds.) Weighing Reasons

(Oxford: OUP).

Markovits, J. (2014) Moral Reason (Oxford: OUP).

Nagel, T. (1970) The Possibility of Altruism (Princeton: PUP).

Nozick, R. (1974) Anarchy, State, and Utopia. Basic Books.

Olson, J. (2006) 'Review of Stephen Darwall's Welfare and Rational Care', Economics and Philosophy, 22(1), $171-77$.

(2011a) In defense of moral error theory. In Michael Brady (ed.), New Waves in Metaethics. Palgrave-Macmillan.

(2011b) 'Error theory and reasons for belief' in Reisner, A. \& Steglich-Petersen, A. (eds.), Reasons for Belief (Cambridge: CUP).

Parfit, D. (1984) Reasons and Persons (Oxford: OUP). 
(1997) 'Reasons and Motivation', in Proceedings of the Aristotelian Society, Supplementary Volume 71, 99-130.

Railton, P. (1989) 'Naturalism and Prescriptivity', Social Philosophy and Policy, 7 (1).

Ridge, M. (2017) Reasons for action: Agent-neutral vs. Agent-relative. The Stanford Encyclopedia of Philosophy.

Rosati, C. (1995a) 'Naturalism, Normativity, and the Open Question Argument', Nô̂s, 29 (1), 46-70. (1995b) 'Persons, perspectives, and full information accounts of the good'. Ethics 105 (2):296325.

(1996) 'Internalism and the Good for a Person', Ethics, 106(2), 297-326. (manuscript) 'Welfare and Rational Fit'.

Scanlon, T. M. (1998) What We Owe to Each Other (Cambridge, Mass.: HUP).

Schroeder, M. (2005) 'Realism and reduction: The Quest for robustness', Philosophers' Imprint, 5, 1-18. (2007) Slaves of the Passions (Oxford: OUP).

(2015) 'Is Knowledge Normative?' Philosophical Issues 25 (1):379-395.

Smith, M. (1994) The Moral Problem (Oxford: Blackwell).

Streumer, B. (2017) Unbelievable Errors (Oxford: OUP).

Stroud, S. (1998) 'Moral Overridingness and Moral Theory', Pacific Philosophical Quarterly, 79, 170-89.

Svavarsdóttir, S. (1999) 'Moral cognitivism and motivation', The Philosophical Review, 108, 161-219.

Sylvan, K. (2018) 'Knowledge as a Non-Normative Relation' Philosophy and Phenomenological Research, 97, (1):190-222.

Tiffany, E. 2007. "Deflationary Normative Pluralism", Canadian Journal of Philosophy 37 Supplement [vol. 33], 231-262.

Williams, B. (1981) "Internal and External Reasons," in Moral Luck (Cambridge: CUP), 101-13.

Worsnip, A. (2018) 'Eliminating Prudential Reasons' in M. Timmons (ed.) Oxford Studies in Normative Ethics (Oxford: OUP), 236-257. 